Research Article

\title{
Investigation of the Performance of Ceramic Fiber Modified Asphalt Mixture
}

\author{
Xiushan Wang $\mathbb{D},{ }^{1}$ Hengyu Zhou $\mathbb{D}^{1},{ }^{1}$ Xingxing $\mathrm{Hu}^{2}$ Senjie Shen, ${ }^{1}$ and Bowen Dong ${ }^{1}$ \\ ${ }^{1}$ School of Civil Engineering and Architecture, Zhejiang Sci-Tech University, Hangzhou, China \\ ${ }^{2}$ Zhejiang Titan Design \& Engineering Co., LTD, Hangzhou, China \\ Correspondence should be addressed to Hengyu Zhou; captain_jock@163.com
}

Received 7 September 2020; Revised 19 January 2021; Accepted 31 January 2021; Published 11 February 2021

Academic Editor: Daniele Baraldi

Copyright ( 2021 Xiushan Wang et al. This is an open access article distributed under the Creative Commons Attribution License, which permits unrestricted use, distribution, and reproduction in any medium, provided the original work is properly cited.

Ceramic fiber (CF) is a novel thermally resistant material with the potential to improve the high-temperature performance of asphalt mixture. In this study, asphalt mixtures with $0 \%, 0.1 \%, 0.2 \%, 0.3 \%, 0.4 \%$, and $0.5 \%$ CFs were prepared. The Marshall test, wheel tracking test, Marshall immersion test, freeze-thaw splitting test, and low-temperature bending test were conducted to evaluate the performance of the CF-modified asphalt mixture. The morphologies of these asphalt mixtures were observed using scanning electron microscopy to analyze the modification mechanism. The results showed that the CFs could improve the mechanical properties, high-temperature stability, moisture susceptibility, and low-temperature cracking resistance of asphalt mixture, with the optimum CF content being $0.4 \%$. Further microscopic analysis showed that the CFs improved the performances of asphalt mixture through forming three-dimensional network structure, asphalt absorption, bridging cracks, and pullingout effect.

\section{Introduction}

Asphalt mixture is the most widely used material for pavement construction. However, the asphalt pavements are prone to deformation under the combined effects of heavy loads and high temperatures. In addition, water-related damages such pothole formation, loosening, and stripping often occur in humid areas, thus reducing the service life of asphalt pavements $[1,2]$. Current reinforcing methods for asphalt mixtures include incorporating additives such as polymers and fibers [3-5]. However, high costs and complex preparation processes limit the utilization of polymeric reinforcing. In contrast, owing to their excellent reinforcement effects and convenient preparation processes, fibers have attracted considerable attention as additives to asphalt mixtures $[6,7]$.

Inorganic fibers are mostly made from minerals, which are characteristic of high strength and low density. In recent years, various types of inorganic fibers have been studied for improving the performance of asphalt mixtures [8-10]. Morea et al. [11] found that using glass macrofibers in asphalt mixtures can improve their low-temperature cracking and rut resistance. Moghadas et al. [12] investigated the Marshall stability and fatigue properties of carbon-fibermodified asphalt mixtures and found that carbon fibers significantly improved the mechanical performance of the asphalt mixtures. Gao et al. [13] stated that basalt fibers improved the permanent deformation resistance, rut resistance, and dynamic stability of asphalt mixtures. Chukla et al. [14] used glass fibers to modify asphalt mixtures and reported that the glass fibers improved the fatigue resistance and permanent deformation resistance of asphalt mixtures. Xiong et al. [15] investigated the influence of brucite fibers on asphalt mixtures, reporting improvement in the rut resistance, moisture susceptibility, and low-temperature cracking resistance of asphalt mixtures. Wang et al. [16] evaluated the performance of porous asphalt mixtures modified with chopped basalt fibers and determined the optimal fiber length and content for improving the properties. In addition, previous research has indicated that asbestos fibers can improve the mechanical properties and thermal resistance of asphalt mixtures. However, asbestos 
fibers pose health hazards, thus limiting their application [17-19].

Ceramic fibers $(\mathrm{CFs})$ are prepared from clay clinker melted at high temperatures and blown into continuous fiber using high-speed airflow, which are a good substitute for asbestos fibers. CFs have excellent mechanical properties like other inorganic fibers such as basalt fibers and glass fibers. In addition, CFs constitute a new type of heat insulation material with working temperatures of $1000-1600^{\circ} \mathrm{C}$; they are widely used in metallurgy, construction, machinery, aerospace, and other fields [20, 21]. In recent years, some researchers have used CFs as building materials to reinforce Portland cement, concrete, asphalt binder, and asphalt mixtures. Ma et al. [22] investigated the mechanical properties and durability of CF-reinforced Portland cement using the wet-hot accelerating method. Su et al. [23] used the split Hopkinson pressure bar system to evaluate the dynamic properties of CF-reinforced concrete and found that ceramic fibers significantly enhanced the dynamic strength and elastic modulus of concrete. Wan et al. [24] used CFs to modify asphalt binders and reported that the CFs enhanced the high-temperature stability and stiffness of the asphalt binder. Arabani et al. [25] performed dynamic shear rheometer and bending beam rheometer tests and found that the addition of CFs significantly improved the high-temperature performance but slightly deteriorated the low-temperature performance of the asphalt binder. Arabani et al. [26] also showed that CFs improved the fatigue resistance and rut resistance of asphalt mixtures, proving that CFs can be used as additives to successfully reinforce asphalt mixtures. Although many studies have investigated the application of $\mathrm{CFs}$ as reinforcing agents in asphalt binders, the performance of CF-modified asphalt mixtures has not been comprehensively analyzed.

In this study, the mechanical properties, high-temperature stability, moisture susceptibility, and low-temperature cracking resistance of asphalt mixtures with different $\mathrm{CF}$ contents were evaluated to verify the reinforcement of $\mathrm{CF}$ on asphalt mixture. Further, the modification mechanism of the CFs was analyzed through microscopic observations. The main purpose of this study is to improve the road performance of asphalt mixture and promote the application of CFs in asphalt pavement.

\section{Materials and Methods}

\subsection{Materials}

2.1.1. Asphalt. Shell AH-70 asphalt used in this study was produced by Jiayue Petrochemical Industry (Hangzhou, China). The characteristics of the asphalt determined in accordance with the ASTM standard tests are presented in Table 1.

2.1.2. Aggregates. The coarse aggregate, fine aggregate, and mineral powder are limestone, which were supplied by Zhengfang traffic construction Co., Ltd. (Jinhua, China). The technical parameters of aggregates are presented in Table 2.
2.1.3. Fibers. CFs used in this study were supplied by Zhongying Chemical Co., Ltd. (Langfang, China). Their characteristics are presented in Table 3. The appearance and micrograph of the ceramic fibers are shown in Figure 1.

2.1.4. Asphalt Mixture. The gradation of the asphalt mixtures used in this experiment is AC-13, as shown in Figure 2. Generally, additives are added to asphalt mixture through dry- and wet-mixing methods. In the dry-mixing method, additives are mixed with coarse and fine aggregates before adding the asphalt and mineral powder. In the wet-mixing method, additives are added to the asphalt before mixing them with the aggregates. As the wet-mixing method is complex and can cause uneven fiber distribution, the drymixing method was used to prepare the asphalt mixtures. The aggregates were first heated in an oven for $4 \mathrm{~h}$ and subsequently mixed with CFs in a blender for $90 \mathrm{~s}$. Thereafter, the asphalt and mineral powder were placed in the blender, and the mixture was stirred for an additional $180 \mathrm{~s}$ to obtain a homogeneous mixture.

\subsection{Test Method}

2.2.1. Marshall Test. The Marshall parameters including optimum asphalt content (OAC), bulk specific gravity, air void volume $(\mathrm{VV})$, voids in mineral aggregates (VMA), Marshall stability, and flow value were obtained by the Marshall test in accordance with JTG E20-2011 [27]. The Marshall specimens with $63.5 \mathrm{~mm}$ in height and $101.6 \mathrm{~mm}$ in diameter were prepared under 75 blows per side using a Marshall compactor (MDJ-II).

2.2.2. Wheel Tracking Test. The wheel tracking test was carried out to evaluate the high-temperature stability of the CF-modified asphalt mixture in accordance with JTG E202011 [27]. For this test, specimens measuring $300 \mathrm{~mm} \times 300 \mathrm{~mm} \times 50 \mathrm{~mm}$ were fabricated and compacted using the wheel-rolling method. For each group of tests, three horizontal samples were prepared under the same conditions. The tests were performed using a wheel tracking tester STCZ-1 under a constant load of $0.7 \mathrm{MPa}$ at $60^{\circ} \mathrm{C}$. The dynamic stability, which is the parameter determined in the wheel tracking test, is defined as the number of load cycles corresponding to every $1 \mathrm{~mm}$ deformation of the mixture. The dynamic stability is calculated as follows:

$$
\text { DS }=\frac{\left(t_{2}-t_{1}\right) \times N}{d_{2}-d_{1}},
$$

where DS is the dynamic stability of the asphalt mixture (times $/ \mathrm{mm}$ ); $t_{2}$ and $t_{1}$ are 60 and $45 \mathrm{~min}$, respectively; $d_{2}$ and $d_{1}$ are the deformations at time $t_{2}$ and $t_{1}(\mathrm{~mm})$, respectively; and $N$ is the loading speed of the test wheel, which is 42 times/min.

2.2.3. Marshall Immersion Tests. Marshall immersion tests were performed to evaluate the water stability of the asphalt mixture in accordance with the JTG E20-2011 [27]. The 
TABLE 1: Physical properties of AH-70 asphalt.

\begin{tabular}{lcc}
\hline Test & Standard & Result \\
\hline $25^{\circ} \mathrm{C}$ penetration $(0.1 \mathrm{~mm})$ & ASTM D5 \\
Softening point $\left({ }^{\circ} \mathrm{C}\right)$ & ASTM D36 & 48 \\
$15^{\circ} \mathrm{C}$ ductility $(\mathrm{cm})$ & ASTM D113 & 108 \\
Flash point $\left({ }^{\circ} \mathrm{C}\right)$ & ASTM D92 & 342 \\
Specific gravity $\left(\mathrm{g} / \mathrm{cm}^{3}\right)$ & ASTM D70 & 1.028 \\
RTFO & ASTM D2872 \\
Mass loss $(\%)$ & ASTM D2872 & 0.4 \\
$25^{\circ} \mathrm{C}$ penetration ratio $(\%)$ & ASTM D5 \\
$15^{\circ} \mathrm{C}$ ductility $(\mathrm{cm})$ & ASTM D113 & 68 \\
\hline
\end{tabular}

TABLe 2: Physical properties of aggregates.

\begin{tabular}{lcc}
\hline Test & Standard & Result \\
\hline Coarse aggregate & & \\
Specific gravity & ASTM C127 & 2.65 \\
Water absorption (\%) & ASTM C127 & 0.66 \\
Los Angeles abrasion (\%) & ASTM C131 & 19.7 \\
Needle and flake particles (\%) & ASTM D4791 & 10.6 \\
Fine aggregate & & \\
Specific gravity & ASTM C128 & 2.69 \\
Sand equivalent (\%) & ASTM T176 \\
Fine aggregate angularity (\%) & ASTM C1252 & 41.1 \\
\hline
\end{tabular}

Table 3: Performance indexes of ceramic fibers.

\begin{tabular}{lccccc}
\hline Fiber type & Length $(\mathrm{mm})$ & Diameter $(\mu \mathrm{m})$ & Density $\left(\mathrm{g} / \mathrm{cm}^{3}\right)$ & Maximum working temperature $\left({ }^{\circ} \mathrm{C}\right)$ & Tensile strength $(\mathrm{MPa})$ \\
\hline Ceramic fiber & $2-4$ & $2-3$ & 1.8 & 1600 & 3000 \\
\hline
\end{tabular}

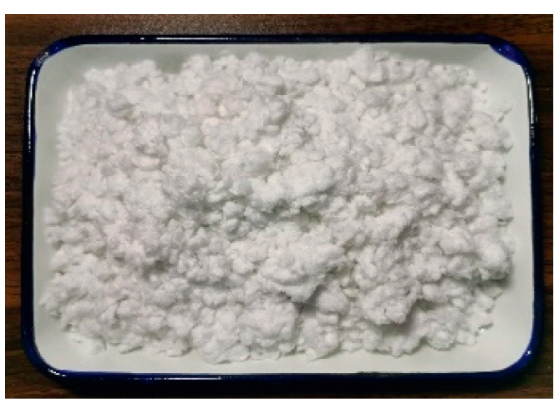

(a)

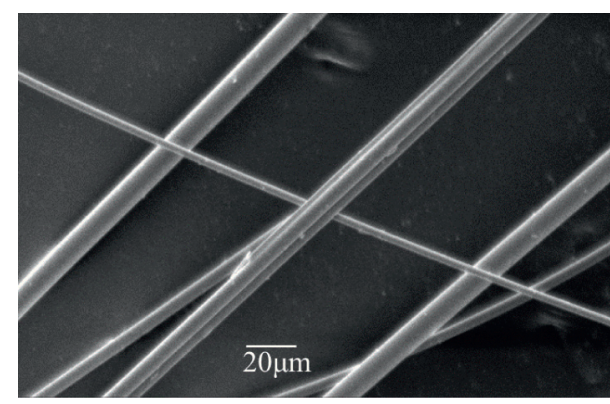

(b)

Figure 1: Appearance and micrograph of ceramic fibers.

Marshall specimens were divided into two groups, each with five horizontal specimens. The experimental group were immersed in a water bath at $60^{\circ} \mathrm{C}$ for $48 \mathrm{~h}$. The control group were immersed in a water bath at $60^{\circ} \mathrm{C}$ for $30 \mathrm{~min}$. Then, the Marshall stability of all specimens was recorded. The immersion residual stability refers to the ratio between the Marshall stabilities of the wet and dry specimens, which is calculated as follows:

$$
\mathrm{MS}_{0}=\frac{\mathrm{MS}_{1}}{\mathrm{MS}} \times 100,
$$

where $\mathrm{MS}_{0}$ is the immersion residual stability (\%), and $\mathrm{MS}_{1}$ and MS are the Marshall stability of the sample with water immersion for $30 \mathrm{~min}$ and $48 \mathrm{~h}(\mathrm{MPa})$, respectively.
2.2.4. Freeze-Thaw Splitting Test. Freeze-thaw splitting tests were conducted to evaluate the moisture susceptibility of asphalt mixtures in accordance with JTG E202011 [27]. For this test, the Marshall specimens were prepared under 50 blows per side using the Marshall compactor. The specimens were divided into two groups, each with five horizontal specimens. The experimental group were placed in a refrigerator at $-18^{\circ} \mathrm{C}$ for $16 \mathrm{~h}$ after vacuum saturation for $15 \mathrm{~min}$ under $97.3-98.7 \mathrm{kPa}$ and then immediately placed in a water bath at $60^{\circ} \mathrm{C}$ for $24 \mathrm{~h}$. All specimens were immersed in a water bath for $2 \mathrm{~h}$, and then their indirect tensile strength (ITS) was measured. The tensile strength ratio (TSR) represents the ratio between the ITS values of a freeze-thaw-cycled specimen and 


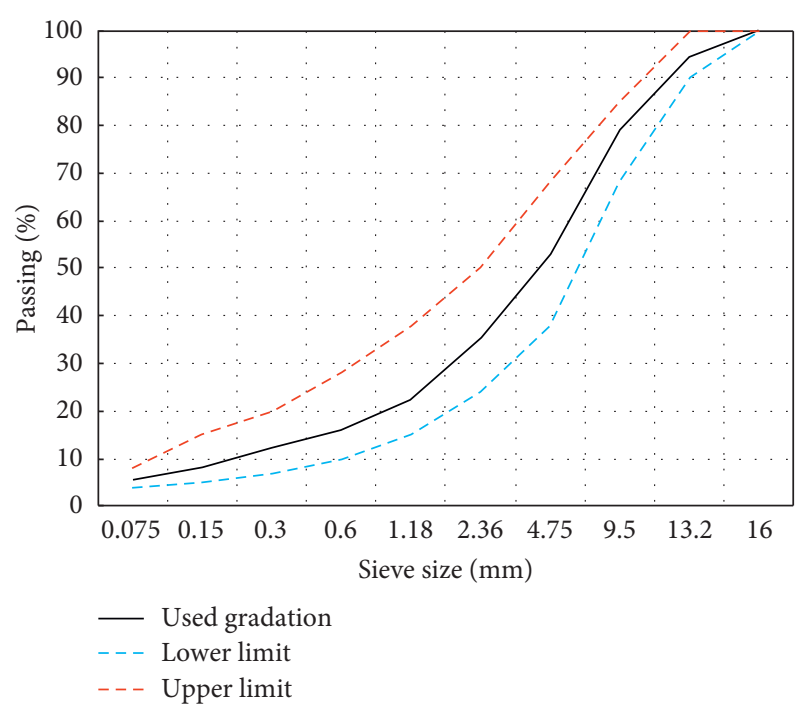

FIgURE 2: Mix proportion of AC-13.

an untreated specimen which was calculated using the following formula:

$$
\mathrm{TSR}=\frac{R_{T 2}}{R_{T 1}} \times 100,
$$

where TSR is the tensile strength ratio (\%), $R_{T 2}$ and $R_{T 1}$ are the indirect tensile strengths of the sample subjected to the freeze-thaw treatment and not subjected to freeze-thaw treatment $(\mathrm{MPa})$, respectively.

2.2.5. Low-Temperature Bending Test. The low-temperature bending test was conducted to evaluate the low-temperature cracking resistance of asphalt mixtures using a material testing system in accordance with JTG E20-2011 [27]. Beam specimens measuring $30 \mathrm{~mm} \times 35 \mathrm{~mm} \times 250 \mathrm{~mm}$ were cut from the specimens used for the wheel tracking test. For each group of tests, five horizontal specimens were prepared under the same conditions. After curing at $-10^{\circ} \mathrm{C}$ for $1 \mathrm{~h}$, the specimens were placed on two fulcrums that were placed $200 \mathrm{~mm}$ apart. A concentrated load was applied at the midspan of the specimen at a rate of $50 \mathrm{~mm} / \mathrm{min}$ until cracking failure occurred. The failure strain reflects the deformation capability of the asphalt mixture, which is calculated as follows:

$$
\varepsilon_{B}=\frac{6 \times h \times d}{L^{2}},
$$

where $\varepsilon_{B}$ is the failure strain $(\mu \varepsilon), h$ is the height of the cross section $(\mathrm{mm}), d$ is the midspan deflection at fracture of the specimen $(\mathrm{mm})$, and $L$ is the span of the specimen $(\mathrm{mm})$.

2.2.6. Scanning Electron Microscopy (SEM). The morphologies of the CF-modified asphalt mixtures were analyzed using scanning electron microscopy (SEM) (Japanese JSM5610LV). After Marshall tests, small fragments were taken from the fracture surfaces of the mixtures as samples. As the samples are not conductive, the surface charge is easy to accumulate and discharge. A JFC-1600-type carbon coater (Japan Electronics Company) was used to coat the samples with gold at a current of $10 \mathrm{~mA}$ for $40 \mathrm{~s}$. Finally, the samples were placed on the testbed for analysis.

\section{Results and Discussion}

3.1. Marshall Test. Figure 3 shows the optimal asphalt contents (OWCs) of the asphalt mixtures with different CF contents $(0 \%, 0.1 \%, 0.2 \%, 0.3 \%, 0.4 \%$, and $0.5 \%)$, which were $5.10 \%, 5.19 \%, 5.26 \%, 5.33 \%, 5.38 \%$, and $5.40 \%$, respectively. CFs with large specific surface area can absorb a part of asphalt binder, thus increasing the asphalt content.

Figure 4 shows the bulk specific gravity of the asphalt mixtures with different CF contents, and the range of the value of bulk specific gravity is 2.351 to 2.370 . The bulk specific gravity decreases with the increase in CF content, because the density of CFs is much smaller than that of asphalt and aggregates. In addition, an increase in CFs and OWC reduces the density of asphalt mixture under the same compaction condition.

Figure 5 shows the VV increases with the increase in CF content. The reason for this phenomenon is that the asphalt mixture with CFs is more difficult to compact than the asphalt mixture without CFs because of the high elastic modulus of CF.

As shown in Figure 6, the VMA increases with the increase in CF content, due to the decrease in bulk specific gravity [19].

As shown in Figure 7, the Marshall stability increases initially and then decreases with the increase in CF content. When the CF content was $0.4 \%$, the Marshall stability of the asphalt mixture increased by $17.5 \%$, demonstrating that the CFs distributed the external force acting on the asphalt mixture [26]. In addition, excessive CFs may disperse unevenly and coagulate together, breaking the three-dimensional network structure of CFs in asphalt mixture.

Figure 8 shows the flow value increases with the increase in CF content, as higher asphalt content results in higher flow value. In contrast, Arabani reported that the flow value decreased with the increase of CF content, because the CFs enhanced the stiffness of the asphalt mixture [26]. The reason for the increase of flow value in this test possibly because the pulling-out effect of CFs improves the toughness of the asphalt mixture. In addition, different gradation and compaction conditions will also cause differences in flow value results.

3.2. Wheel Tracking Test. Figure 9 shows the results of the wheel tracking tests. As shown in Figure 9, the dynamic stability increases and the rut depth decreases as the CF content increases. When the CF content is $0.5 \%$, the hightemperature performance of the asphalt mixture is the best. The dynamic stability improves by $27.3 \%$ and the rut depth decreases by $23.1 \%$ compared with that of the asphalt mixtures with no fiber, indicating that CFs can significantly improve the high-temperature stability of asphalt mixtures. CFs in asphalt mixture can absorb light components of 


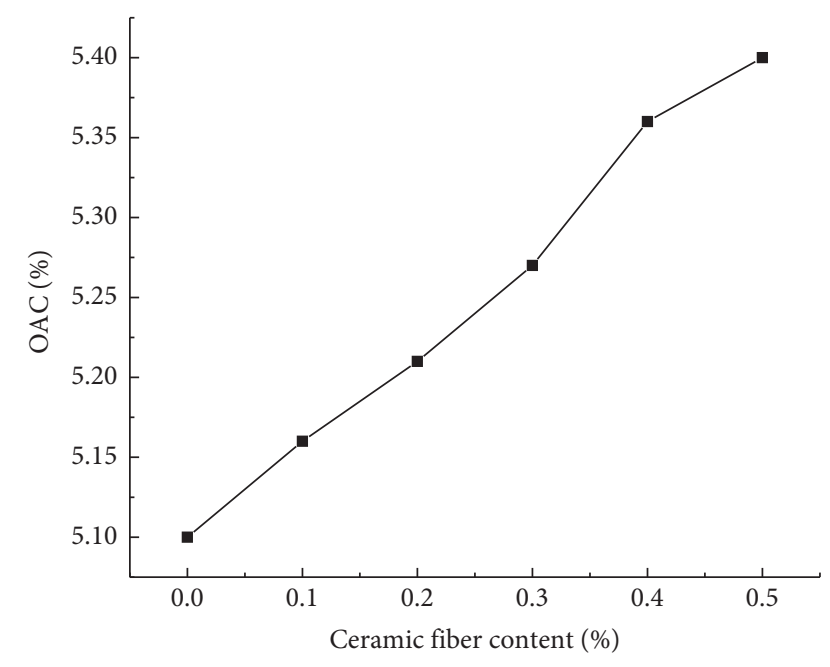

FIgUre 3: Relation between OAC and CF content.

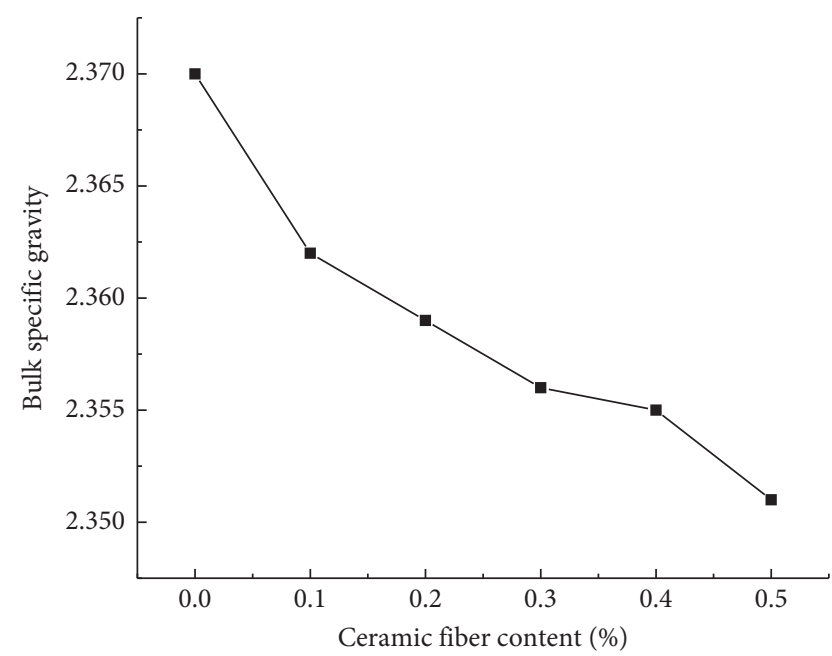

FIGURE 4: Relation between bulk specific gravity and CF content.

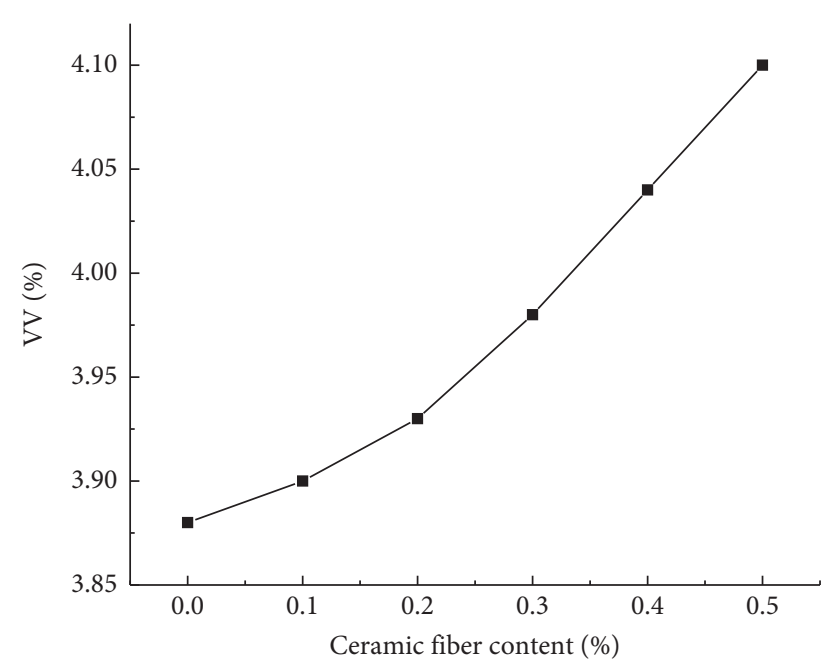

FIGURE 5: Relation between VV and CF content.

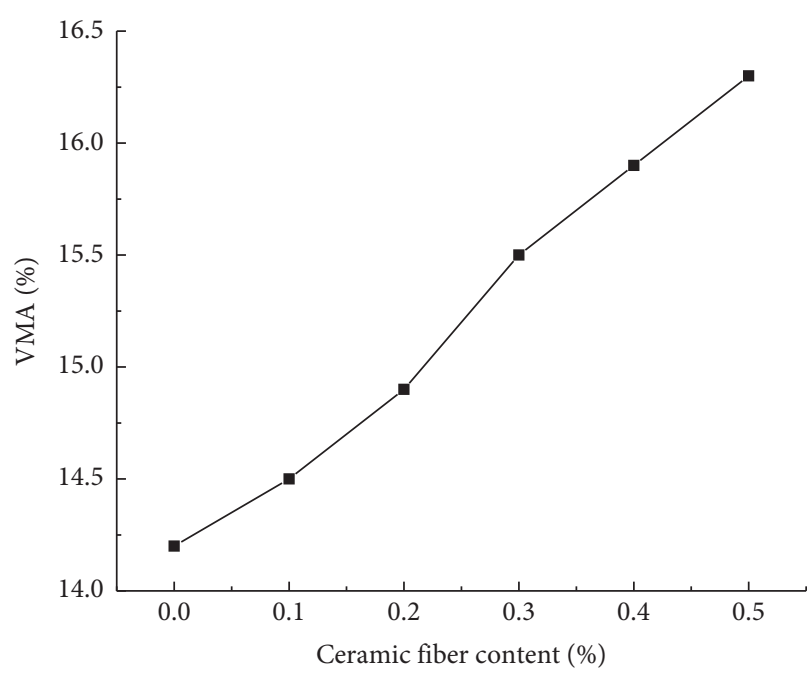

Figure 6: Relation between VMA and CF content.

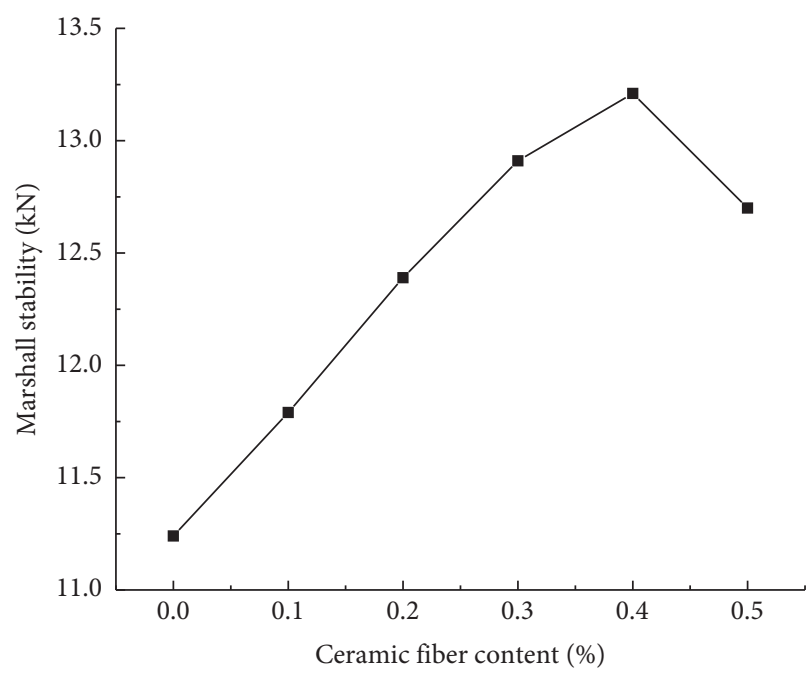

Figure 7: Relation between Marshall stability and CF content.

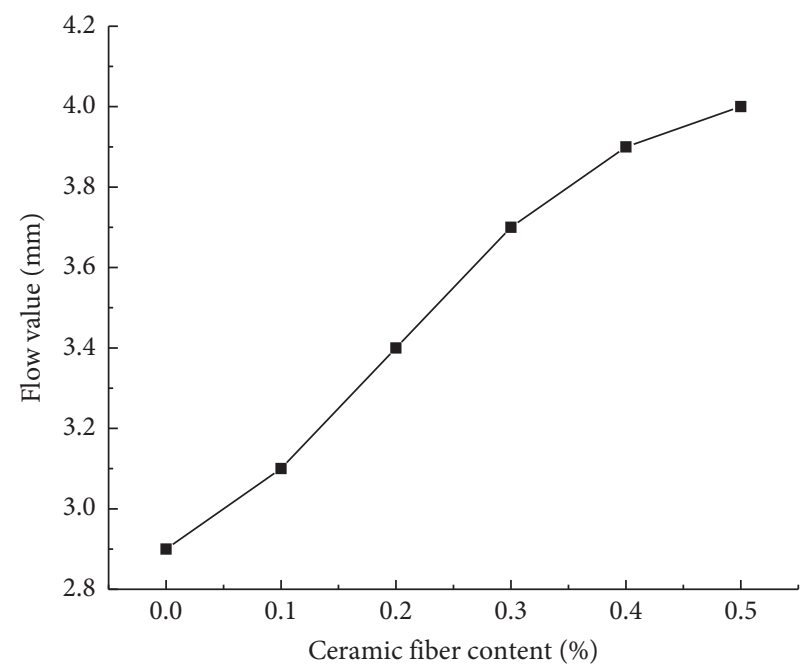

FIGURE 8: Relation between flow value and CF content. 


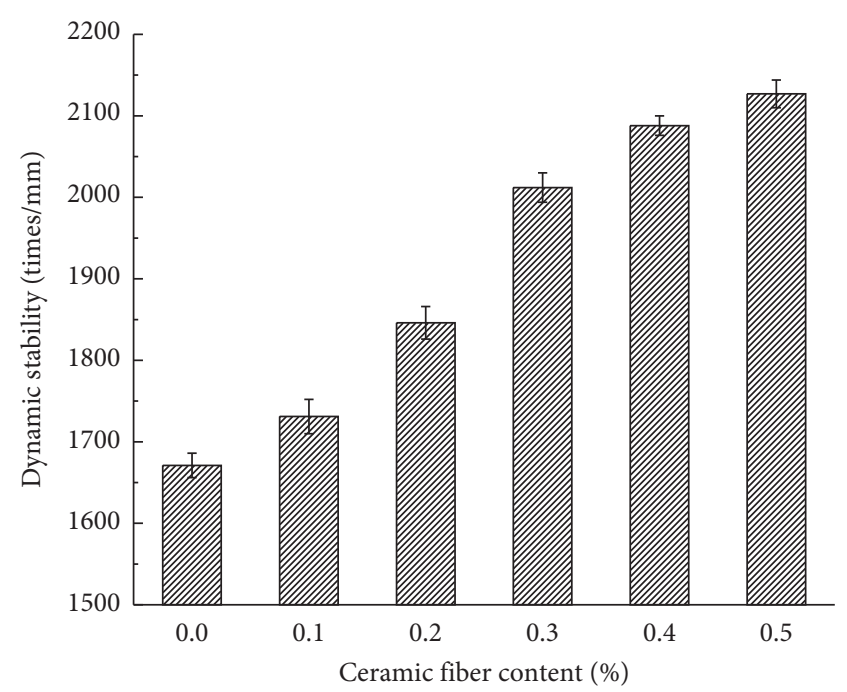

(a)

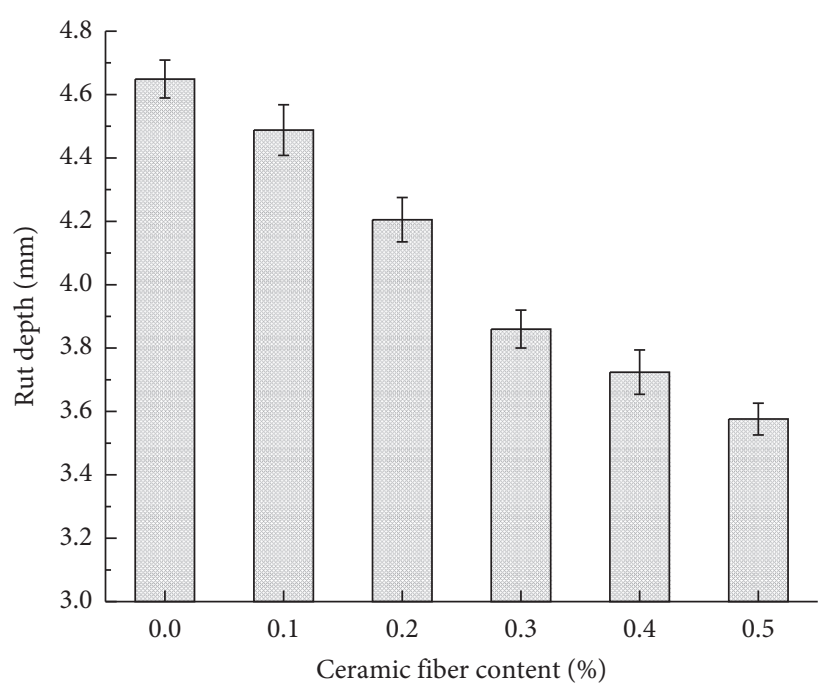

(b)

FIgure 9: Results of wheel tracking test. (a) Dynamic stability. (b) Rut depth.

asphalt and transform the free asphalt to structural asphalt; thus, the temperature sensitivity of asphalt is reduced and the stiffness of asphalt is enhanced [24]. Furthermore, the CFs form a three-dimensional network structure in asphalt mixture, which can limit the relative slippage of the aggregates and improve the deformation resistance of the asphalt mixture. Compared with basalt fibers and glass fibers, CFs have lower thermal conductivity and lower density; therefore, CFs have good thermal stability and a larger specific surface area at the same content, thus mitigating heat transfer in asphalt mixtures and absorbing more light components of asphalt [24].

3.3. Marshall Immersion Test. Figure 10 presents the Marshall stability, immersion Marshall stability, and immersion residual stability of asphalt mixtures with different $\mathrm{CF}$ contents. It can be seen that the Marshall stability of the asphalt mixtures sharply decreased after immersing in a water bath for $48 \mathrm{~h}$. This is because moisture damaged the interface between the asphalt and aggregates and weakened their bond strength. As shown in Figure 10, the immersion residual stability first increases and then decreases with the increase in CF content, and it reaches the highest value at a $\mathrm{CF}$ content of $0.4 \%$. The immersion residual stability of CFmodified asphalt mixture improved by $6.4 \%$ compared with that of asphalt mixture without $\mathrm{CFs}$, indicating that the water stability of asphalt mixture can be improved. The absorption of CFs increases the viscosity of the asphalt binder and enhances the bonding strength between the asphalt and aggregates, which improves the stripping resistance between asphalt and aggregates. Nevertheless, excessive amounts of CFs can cause uneven fiber dispersion and increase the porosity of the asphalt mixtures, resulting in a negative effect on the water stability of asphalt mixtures.

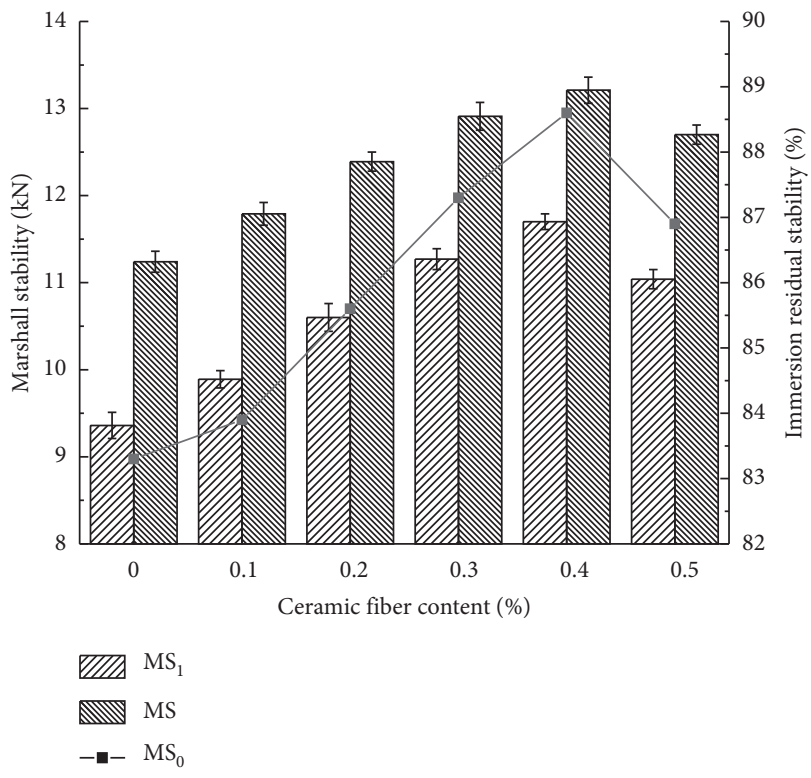

Figure 10: Results of Marshall immersion test.

3.4. Freeze-Thaw Splitting Test. The freeze-thaw splitting test results are shown in Figure 11. After freeze-thaw cycling, the ITS of the asphalt mixtures decreases significantly. Because the saturated liquid in the pores freezes at low temperatures, the volume expansion increases the pore pressure, leading to cracking of the internal pores. As shown in Figure 11, the ITS and TSR of asphalt mixtures increase up to a CF content of $0.4 \%$, followed by a decrease. Compared with a pure asphalt mixture, the ITS increased by $20 \%$ and the TSR increased by $8.8 \%$ at a CF content of $0.4 \%$. The results of the freeze-thaw splitting tests are consistent with the Marshall immersion test results, further indicating that the addition of CFs improves the mechanical performance and moisture resistance of asphalt mixtures. 


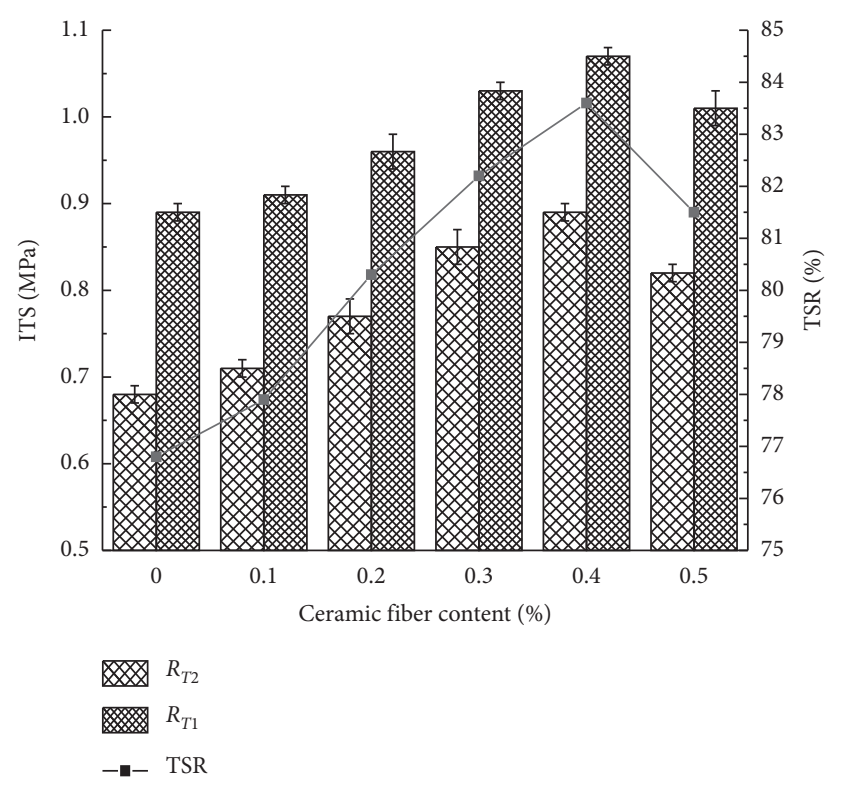

FIGURE 11: Results of the freeze-thaw splitting test.

3.5. Low-Temperature Bending Test. The low-temperature bending test results are shown in Figure 12. The failure strain first increases and then decreases as the CF content increases. When the CF content is $0.4 \%$, the failure strain reaches the highest value of $2566.3 \mu \varepsilon$, showing an improvement of $9.6 \%$ compared with the asphalt mixture without CFs. According to the test results of Arabani, CFs have a negative effect on the low-temperature performance of the asphalt binder [25]. Although there is a negative effect of CFs on the low-temperature performance of asphalt binder, the CFs can play a role in the improvement of the low-temperature performance of asphalt mixtures. The reason is that the $\mathrm{CF}$ in the asphalt mixture can reduce part of the tensions. In addition, CFs can enhance the strength between asphalt binders and aggregates.

Asphalt pavements shrink at low temperatures, and the volume changes induce stress and cause cracking of the asphalt pavements. The CFs increase the viscosity of the asphalt binder and enhance the bonding strength between asphalt and aggregates, which can prevent tensile fracture of asphalt mixtures. In addition, CFs with excellent mechanical properties can bridge cracks in asphalt mixtures, inhibiting the propagation of microcracks. Furthermore, the threedimensional networks formed by CFs facilitate the distribution and transfer of stress, thus preventing stress concentration in asphalt mixtures. But excessive amounts of CFs increase the stiffness and decrease the elastic performance of the asphalt mixture, resulting in the brittleness of the mixture increase and cracks develop more quickly.

3.6. Scanning Electron Microscopy. The morphologies of CFmodified asphalt mixtures observed using SEM are illustrated in Figures 13-15.

As shown in Figures 13(a) and 13(b), the CFs are randomly distributed in the asphalt mixture, forming a stable three-dimensional network structure, which has a

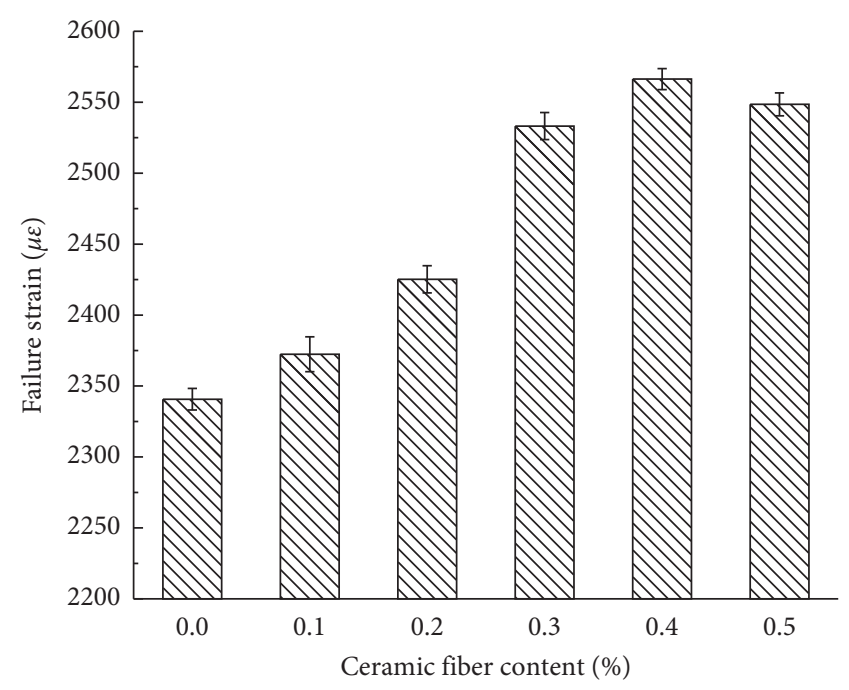

FIGURE 12: Results of low-temperature bending test.

reinforcing effect on the asphalt mixture. When the asphalt mixture is subjected to external forces, CFs can transfer and distribute the stresses acting from different directions, thus preventing cracking caused by stress concentration. As shown in Figure 13(c), the CFs bend under the pressure exerted by the aggregates, increasing the friction between the CFs and aggregates, restraining the relative slippage of aggregates.

As shown in Figure 14, the CFs have a regular cylindrical shape with a large specific surface area which adsorb a large amount of asphalt and form a thick asphalt film, exhibiting adequate wettability with the asphalt binder. The adsorption of CFs transforms the free asphalt into structural asphalt, increasing the viscosity, stiffness, and high-temperature stability of the asphalt mixture. Figure 14(c) shows that the roots of the CFs are tightly bonded to the asphalt through interlocking, indicating a high bonding strength between CFs and asphalt.

Figure 15 shows the internal cracks formed in the asphalt mixtures with and without the CFs. As shown in Figure 15, the width of the crack in no fiber asphalt mixture is about $6.3 \mu \mathrm{m}$, and the width of the crack in the CFs-modified asphalt mixture is about $4.4 \mu \mathrm{m}$. In addition, the longitudinal length of the crack in no fiber asphalt mixture is larger. Therefore, the size of cracks in the asphalt mixture with CFs is obviously smaller than that of asphalt mixtures with no fiber. This is attributed to the fact that the CFs can connect cracks and play the role of bridging and pulling-out. The microscopic force diagram of the bridging and pulling-out effect is shown in Figure 16. The CFs with high elastic moduli can bear tensile loads and impart self-healing properties to asphalt mixtures [26]. The chemical bonding energy and frictional shear force between CFs and asphalt mixture provide the pull-out resistance of CFs. As the tensile stress further increases, CFs separate from the asphalt mixture first, and the chemical bonding energy disappears; subsequently, the friction shear force decreases with the decrease in the shear surface. It can be concluded that the pulling-out process of CFs is not instantaneous. With the participation 


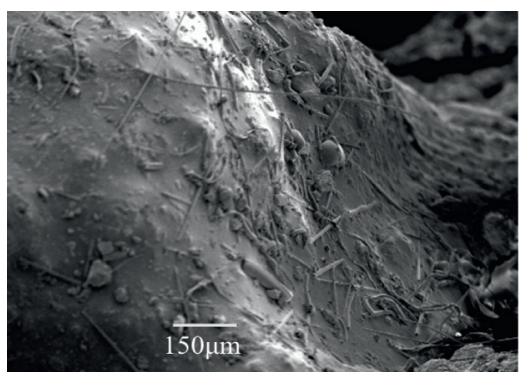

(a)

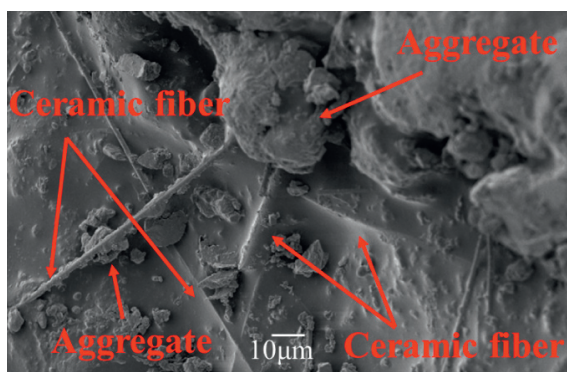

(b)

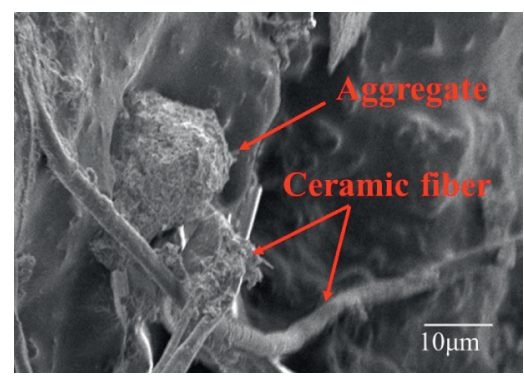

(c)

Figure 13: Three-dimensional network structure of ceramic fibers.

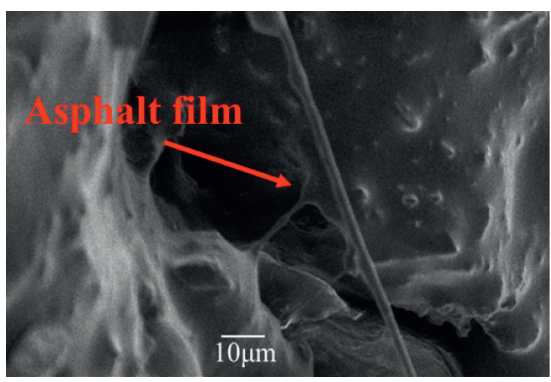

(a)

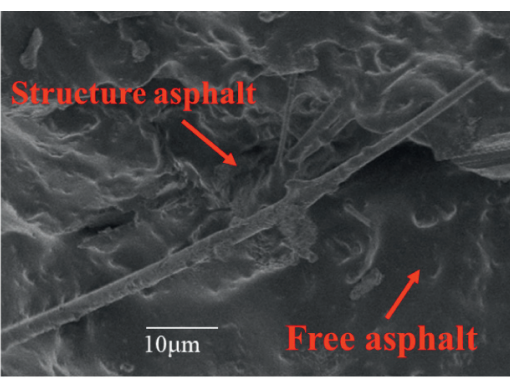

(b)

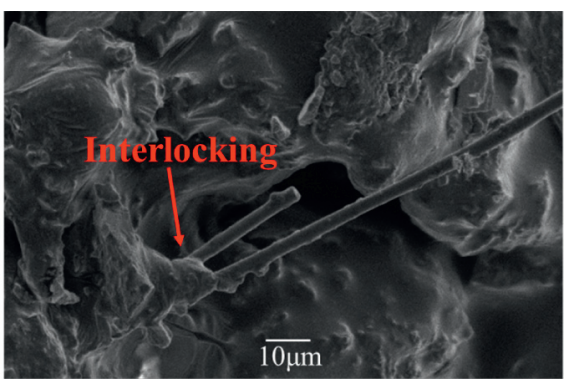

(c)

Figure 14: Adsorption of ceramic fibers.

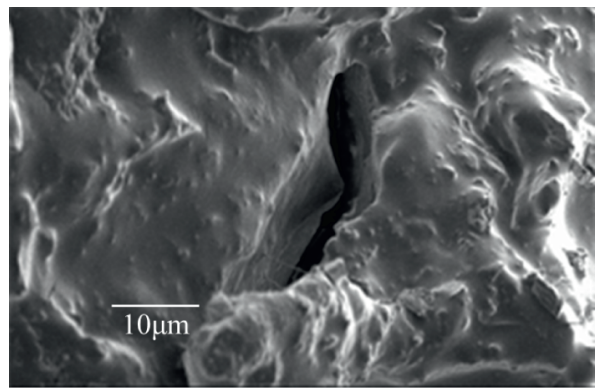

(a)

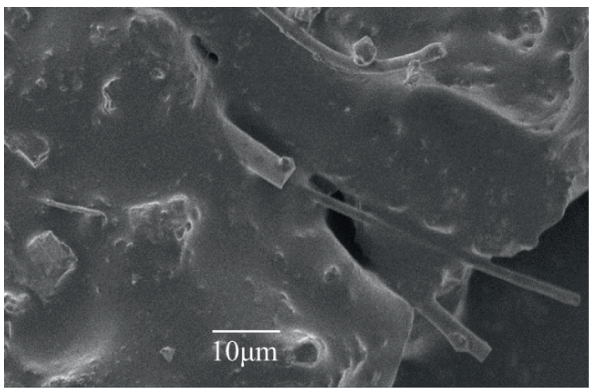

(b)

FIGURE 15: Cracks of asphalt mixture: (a) without ceramic fibers and (b) with ceramic fibers.

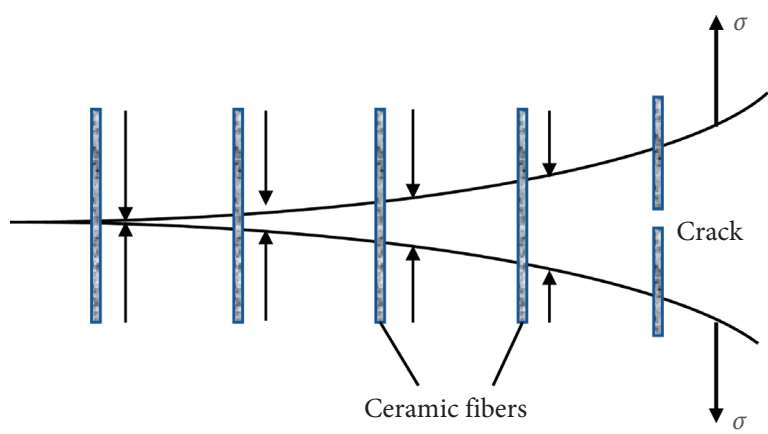

(a)

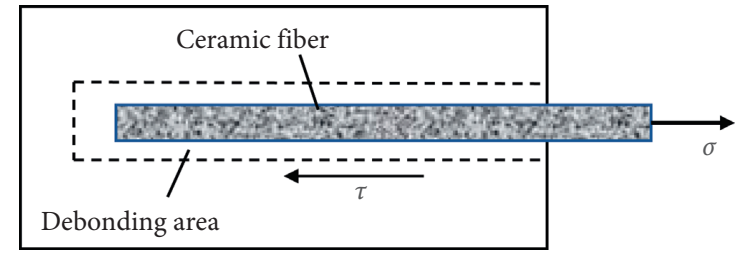

(b)

FIgURE 16: Microscopic force diagram: (a) bridging effect and (b) pulling-out effect. 
of multiple CFs, the pulling-out effect can retard crack propagation, thereby improving the toughness of the asphalt mixtures.

\section{Conclusions}

In this study, the performances of CF-modified asphalt mixtures were evaluated. The following conclusions can be drawn based on the findings of this study:

(1) The addition of CFs can substantially improve the rut resistance and mechanical properties of asphalt mixtures. Compared with asphalt mixtures without CFs, the dynamic stability, Marshall stability, and ITS increased by $27.3 \%, 17.5 \%$, and $20.0 \%$, respectively.

(2) The moisture susceptibility and low-temperature cracking resistance of asphalt mixtures slightly improved by incorporating CFs. The immersion residual stability, TSR, and failure strain increased by $6.4 \%, 8.8 \%$, and $9.6 \%$, respectively, compared with those of the asphalt mixtures without CFs.

(3) The optimal CF content for improving the properties of asphalt mixtures is $0.4 \%$, considering the pavement performance and economic benefits.

(4) SEM analysis showed that the adsorption of CFs, their reinforcing effects, cracking resistance imparted to the asphalt by the CFs, and formation of the three-dimensional network structures in the asphalt mixture improved the pavement performances of the asphalt mixtures.

(5) CFs can be used as a reinforcing material to modify asphalt mixture, which provides a reference for the application of CFs in asphalt pavement construction.

\section{Data Availability}

The data used to obtain the conclusion in this study are available from the corresponding author upon request.

\section{Conflicts of Interest}

The authors declare that there are no conflicts of interest regarding the publication of this paper.

\section{Acknowledgments}

The authors would like to thank the financial support from the Basic Public Welfare Research Project of Zhejiang Province (Grant number: LGF18E080015).

\section{References}

[1] D. Luo, A. Khater, Y. Yue et al., "The performance of asphalt mixtures modified with lignin fiber and glass fiber: a review," Construction and Building Materials, vol. 209, pp. 377-387, 2019.

[2] X. Sun, X. Qin, Q. Chen, and Q. Ma, "Investigation of enhancing effect and mechanism of basalt fiber on toughness of asphalt material," Petroleum Science and Technology, vol. 36, no. 20, pp. 1710-1717, 2018.
[3] M.-M. Wu, R. Li, Y.-Z. Zhang, L. Fan, Y.-C. Lv, and J.-M. Wei, "Stabilizing and reinforcing effects of different fibers on asphalt mortar performance," Petroleum Science, vol. 12, no. 1, pp. 189-196, 2015.

[4] Y. Cheng, C. Zhu, G. Tan et al., "Laboratory study on properties of diatomite and basalt fiber compound modified asphalt mastic," Advances in Materials Science and Engineering, vol. 12, 2017.

[5] X. Zhang, X. Gu, J. Lv, Z. Zhu, and F. Ni, "Mechanism and behavior of fiber-reinforced asphalt mastic at high temperature," International Journal of Pavement Engineering, vol. 19, no. 5, pp. 407-415, 2018.

[6] X. Qin, A. Shen, Y. Guo, Z. Li, and Z. Lv, "Characterization of asphalt mastics reinforced with basalt fibers," Construction and Building Materials, vol. 159, pp. 508-516, 2018.

[7] H. Ziari, Y. Saghafi, A. Moniri et al., "The effect of polyolefinaramid fibers on performance of hot mix asphalt," Petroleum Science and Technology, vol. 12, pp. 1-7, 2019.

[8] B. Guan, R. Xiong, R. He et al., "Investigation of usability of brucite fiber in asphalt mixture," International Journal of Pavement Research and Technology, vol. 7, no. 3, p. 193, 2014.

[9] Y. Xue and Z. Qian, "Development and performance evaluation of epoxy asphalt concrete modified with mineral fiber," Construction and Building Materials, vol. 102, pp. 378-383, 2016.

[10] Q. Xu, H. Chen, and J. A. Prozzi, "Performance of fiber reinforced asphalt concrete under environmental temperature and water effects," Construction and Building Materials, vol. 24, no. 10, pp. 2003-2010, 2010.

[11] F. Morea and R. Zerbino, "Improvement of asphalt mixture performance with glass macro-fibers," Construction and Building Materials, vol. 164, 2018.

[12] M. Vadood and S. Baeetabar, "Investigating the mechanical properties of carbon fiber-reinforced asphalt concrete," Road Materials and Pavement Design, vol. 15, no. 2, 2014.

[13] C. M. Gao, S. Han, K. X. Zhu, and Z. Y. Wang, "Research on basalt fiber asphalt concrete's high temperature performance," Applied Mechanics and Materials, vol. 505-506, pp. 39-42, 2014.

[14] M. Shukla, D. Tiwari, and K. Sitaramanjaneyulu, "Performance characteristics of fiber modified asphalt concrete mixes," International Journal on Pavement Engineering \& Asphalt Technology, vol. 15, no. 1, 2014.

[15] R. Xiong, J. Fang, A. Xu, B. Guan, and Z. Liu, "Laboratory investigation on the brucite fiber reinforced asphalt binder and asphalt concrete," Construction and Building Materials, vol. 83, 2015.

[16] S. Wang, A. Kang, P. Xiao, B. Li, and W. Fu, "Investigating the effects of chopped basalt fiber on the performance of porous asphalt mixture," Advances in Materials Science and Engineering, vol. 2019, pp. 1-12, 2019.

[17] H. Bushing and D. Antrim, "Fiber reinforcement of bituminous mixtures," Association of Asphalt Paving Technologists, vol. 37, pp. 629-659, 1968.

[18] J. H. Kietzman, "Effect OF short asbestos fibers ON basic physical properties OF asphalt pavement mixes," Highway Research Board Bulletin, vol. 12, 1960.

[19] H. Chen, Q. Xu, S. Chen, and Z. Zhang, "Evaluation and design of fiber-reinforced asphalt mixtures," Materials \& Design, vol. 30, no. 7, 2009.

[20] M. Ebihara, "Dissolution properties of refractory ceramic fiber in aqueous solutions from strong acids to strong bases," Glass Physics and Chemistry, vol. 45, no. 3, pp. 229-231, 2019. 
[21] C. C. Wei, O. Y. Chen, Y. Liu et al., "Ceramic asymmetric hollow fiber membranes-one step fabrication process," Journal of Membrane Science, vol. 320, no. 1-2, pp. 191-197, 2008.

[22] Y. Ma, B. Zhu, M. Tan et al., "Properties of ceramic fiber reinforced cement composites," Cement and Concrete Research, vol. 35, no. 2, pp. 296-300, 2005.

[23] H. Su and J. Xu, "Dynamic compressive behavior of ceramic fiber reinforced concrete under impact load," Construction and Building Materials, vol. 45, pp. 306-313, 2013.

[24] J. Wan, S. Wu, Y. Xiao, Q. Liu, and E. Schlangen, "Characteristics of ceramic fiber modified asphalt mortar," Materials, vol. 9, no. 9, p. 788, 2016.

[25] M. Arabani and A. Shabani, "Evaluation of the ceramic fiber modified asphalt binder," Construction and Building Materials, vol. 205, pp. 377-386, 2019.

[26] M. Arabani, A. Shabani, and G. H. Hamedi, "Experimental investigation of effect of ceramic fibers on mechanical properties of asphalt mixtures," Journal of Materials in Civil Engineering, vol. 31, no. 9, Article ID 04019203, 2019.

[27] People's Communication Press, E Standard Test Methods of Bitumen and Bituminous Mixtures for Highway engineering, People's Communication Press, Beijing, China, 2011. 